\title{
PRESENTACIÓN
}

\section{PENSANDO EL PROCESO CONSTITUYENTE}

Dos años después de fundada la Universidad de Chile, en 1843, nacía la Revista Anales, la más antigua de América Latina y en cuyas páginas se registra de una u otra forma el espíritu de los tiempos. De todos los tiempos: de los tranquilos y de los convulsos. También de aquellos donde los silencios son elocuentes. Elocuencia recogida en números y series de Anales que saltan sorteando aquellos tiempos donde es poco o nada lo que se puede escribir, para luego reescribirlos, releerlos y desafiarlos con la fidelidad de quien se asume como testigo de su época y la pluralidad de enfoques propios del que se debe a la república.

Para iniciar la primavera del 2016, un año en que todos los debates están abiertos, y en medio de lo que se ha caracterizado como la mayor crisis institucional desde la ruptura democrática de 1973, elegimos un tema, una demanda, un acto, un llamado histórico protagonizado por la Presidenta de la República, Michelle Bachelet, cuando a mediados del 2105 convocó al país a un proceso constituyente para una nueva Constitución que reemplace la que en 1980 consagró la dictadura encabezada por Augusto Pinochet.

La pregunta por la legitimidad, la democracia, o la soberanía. Las interrogantes sobre las formas y los trasfondos; acerca de los derechos, o sobre las mayorías y las minorías en este debate sobre una Constitución cuya vigencia hasta hoy ha tenido como correlato el manto de la ilegitimidad sobre los procesos, instituciones y personas durante más de un cuarto de siglo, conducen sin duda a uno de los temas más complejos y trascendentes de los últimos tiempos.

Por ello, y fiel a este espíritu de escuchar las pulsiones de su tiempo, de enfrentarlas e interpelarlas desde distintas miradas, convocamos a un conjunto de académicos e intelectuales a pensar sobre lo que significa este proceso.

Como resultado de este ejercicio a través del cual la Universidad de Chile aporta a un debate fundamental, se inscribe el trabajo del abogado y Profesor Fernando Atria, quien entrega el marco general de este debate; o la pregunta sobre universidad y proceso constituyente asumida por el Decano de la Facultad de Derecho, Davor Harasic.

En la línea de enriquecer y densificar la discusión con diversas miradas está la reflexión sobre la democracia del académico Juan Pablo Arancibia; las ideas relativas 
a la soberanía popular y los procesos constituyentes, de Claudia Heiss; o el análisis sobre la crisis y la oportunidad que se abre ante el proceso constituyente, escrito por el intelectual y Premio Nacional de Humanidades, Manuel Antonio Garretón.

Desde la perspectiva latinoamericana relevamos el texto del destacado intelectual argentino Roberto Gargarella; así como el trabajo de la académica y Directora del Archivo Central Andrés Bello, Alejandra Araya, quien analiza las formas de constituirse en Chile.

La necesaria contextualización en el marco de la historia local está a cargo de la Profesora Sofía Correa, así como las proyecciones de la democracia son abordadas por el filósofo Carlos Ruiz Schneider.

También se incorpora la interrogante por la presencia de otros actores en este proceso, abordada en sendos trabajos de las académicas Alejandra Castillo y Verónica Figueroa Huencho.

Como señaló Andrés Bello en su discurso de instalación de la Universidad, el 17 de septiembre de 1843: "La Universidad, Señores, no sería digna de ocupar un lugar en nuestras instituciones sociales, si (como murmuran algunos ecos oscuros de declamaciones antiguas) el cultivo de las ciencias i de las letras pudiese mirarse como peligroso bajo un punto de vista moral, o bajo un punto de vista político..."

Bajo la premisa contenida en estas palabras de Bello, la Revista Anales de la Universidad de Chile presenta el aporte de un conjunto de mujeres y hombres que, desde la pluralidad de sus disciplinas y saberes, contribuyen con su rigor y lucidez a pensar el país.

Faride Zeran Chelech Directora de Anales de la Universidad de Chile Vicerrectora de Extensión y Comunicaciones Premio Nacional de Periodismo 2007 